\title{
IMPACT OF IMMUNE SUPPRESSION ON HISTOPATHOLOGICAL AND IMMUNOLOGICAL PARAMETERS OF MICE EXPERIMENTALLY INFECTED WITH GIARDIA LAMBLIA

\author{
By
}

\begin{abstract}
HOWAIDA I. H. ISMAIL ${ }^{1}$, DALIA S. ASHOUR ${ }^{1}$, ABEER E. SAAD ${ }^{1 *}$ and OMNIA K. RIZK ${ }^{2}$

Department of Medical Parasitology ${ }^{1}$, and Department of Pathology ${ }^{2}$, Faculty of Medicine, Tanta University, Egypt ( ${ }^{*}$ Correspondence: abero2020@yahoo.com)

\section{Abstract}

Giardiasis is one of the most frequent entero-parasites worldwide; its prevalence is more common in developing countries. Giardia lamblia is considered one of the opportunistic parasites and its clinical manifestations represent the expression of host resistance and parasite virulence. As of chronic giardiasis cases were expected to worsen in immunosuppressed patients with development of various complications. This work assessed the histolopathological and the possible immunological effects of infection with G. lamblia in an immunosuppressed experimental animal model in comparison to immunocompetent one. Mice were divided into 4 groups: group I: immunocompetent (IC) mice infected with G. lamblia cysts, group II: immunosuppressed (IS) mice infected with cysts, group III: uninfected immunocompetent mice and group IV: uninfected immunosuppressed mice. From each group, small intestine was removed for histopathological and molecular studies. Also, cyst counting in the stool of infected mice was estimated. We found that the number of G. lamblia cysts in the stool of IS mice was significantly higher than that from IC ones. Shortening of the villi was more pronounced in the IS than in IC group. Furthermore, intraepithelial lymphocytic count, goblet cell count and mast cell count were significantly decreased in the IS infected group as compared to IC ones. Expression of interleukin-6 mRNA showed high expression in IC infected mice while it was weak in IS mice. In conclusion, the present study revealed the importance of the innate immunity presented by goblet cells, mast cells and other adaptive immunity responses; in the clearance of Giardia.
\end{abstract}

Key words: Giardiasis; immunosuppression; mast cells; IL-6; intraepithelial lymphocytes.

\section{Introduction}

Giardiasis, an intestinal infection caused by Giardia lamblia infection, is one of the most common parasitic diseases worldwide, as it infects approximately 280 million new symptomatic cases per year especially in the developing countries (Lane and Lloyd, 2002; Cotton et al, 2015; Dyab et al, 2016). This infection is directly associated with poor hygienic conditions, poor water quality control, and overcrowding. Reinfection and drug resistance are two major problems in endemic areas (Golami et al, 2016). The transmission of this parasitic disease usually occurs indirectly following ingestion of contaminated food or water with cysts, or directly via the fecal-oral route (Cotton et al, 2015). Clinical manifestations of giardiasis are highly variable, ranging from asymptomatic to symptomatic severe cases (Anuar et $a l, 2015)$. Giardia is a non-invasive parasite of the small intestine, it causes villous atrophy, damage of microvilli and tight junctions and intestinal barrier dysfunction due to apoptosis of enterocytes (Chin et al, 2002; Panaro et al, 2007). As a result, the parasite is interfering with the absorption of nutrients and causes malabsorption, diarrhea, steatorrhoea and weight loss (Hill and Nash, 2015). G. lamblia appears to be an opportunistic parasite with development of various complications as malabsorption syndrome, lactose intolerance, vitamin $\mathrm{B}_{12}$ deficiency and pancreatic insufficiency (Gassama et al, 2001). Moreover, infected individuals can also develop extra-intestinal complications that may affect the joints, the skin, the eyes, and the central nervous system, but the mechanisms still are unknown (Halliez and Buret, 2013).

The risk factors for acquisition of infections are the same in both immunocompetent 
(IC) and immunosuppressed (IS) individuals, but the immune system, through local and systemic responses, plays an integral part in modifying the establishment of infection, limiting the severity and dissemination of the disease, and assisting in clearance of the parasite (Stark et al, 2009). The course of infection is highly variable in children, pregnant women and immunocompromised persons (Faubert, 2000). Many studies reported that humans with immunodeficiencies in the form of common variable immunodeficiency (CVID) and impaired IgA function have an increased risk of developing chronic Giardia infections (Saghaug et al, 2015).

The number of IS individuals continue to increase each year due to many causes as more patients undergoing hematopoietic and organ transplants and treatments with immunosuppressive therapies. Furthermore, although diarrheal diseases may be declining due to improvements in treatment, the total population of people continues to grow, leaving diarrheal diseases remaining as a major problem, especially in the developing world. So, the clinical significance of enteric protozoa in the IS population will continue to grow globally (Stark et al, 2009). In the early phase of infection, the innate immune system acts nonspecifically through different elements that have an antigiardial effect, such as nitric oxide, mucins, defensins and several digestive enzymes (RoxtrömLindquist et al, 2006). Mast cells play a significant role in the protective immune response against Giardia (Lopez-Romero et $a l, 2015)$. Later in the infection, the adaptive immune system is activated and occurs in two major phases: an acute or cellular phase, which is T-cell dependent and associated with production of various cytokines as IL6 , IL-4, IL-5 and IFN- $\gamma$, followed by an antibody dependent or B-cell-dependent phase. This phase is presented by production of parasite-specific antibodies of the IgA isotype (Faubert, 2000; Langford et al, 2002; Grit et al, 2014).
Cytokines act as a bridge between innate and adaptive immune responses. IL-6, which is derived from dendritic cells (DC), is a major cytokine in the defense against giardiasis; it modulates B-cell maturation and switching to produce IgA, and it also mediates T-cell differentiation (Scheller et al, 2011; Kamda et al, 2012).

This study aimed to assess the histolopathological and the possible immunological effects of infection with $G$. lamblia in an immunosuppressed experimental animal model in comparison to immunocompetent one.

\section{Materials and methods}

Experimental animals and parasite: Sixty laboratory-bred, parasite-free male Swiss albino mice (18-20 $\mathrm{g}$ in weight, 6-8 weeks old) were used. Mice were maintained under standard laboratory conditions in accordance to the national and institutional guidelines with special care to food and water to ensure that no other sources of infection were introduced to these animals throughout the course of the study. Thirty mice were immunosuppressed by intraperitoneal injection of cyclophosphamide in a dose of 20 $\mathrm{mg} / \mathrm{kg} /$ day for five days (El-Kowrany et al, 1996).

Giardia lamblia cyst suspension was prepared (Cheesbrough, 1987), in which cysts were separated from diarrheic stool samples of heavily infected patients attending Tanta University Hospital. and suspended in saline. Each mouse was infected orally by $1 \times 10^{5}$ G. lamblia cysts.

Experimental design and sampling: Mice were divided into 4 groups: GI (IC \& infected); 20 immunocompetent (IC) mice infected with G. lamblia cysts, GII (IS \& infected): 20 immunosuppressed (IS) mice infected with $G$. lamblia cysts, GIII (control IC):10 uninfected immunocompetent mice and GIV (control IS):10 uninfected immunosuppressed mice.

At two and four weeks post infection: A two-hour stool samples were collected from 10 infected mice at a time (each mouse sepa- 
rately) for cyst counting. Then mice sacrificed and the upper $6 \mathrm{~cm}$ of the duodenum and proximal jejunum were dissected, removed and divided into two parts. One part was fixed in $10 \%$ formol-saline and embedded in paraffin wax for histopathological examination. The second part was preserved at $-70^{\circ} \mathrm{C}$ for detection of IL- 6 by PCR. Mice of the control groups (III \& IV) were sacrificed at the end of the experiment and processed as above.

Cyst counting in stool of mice: Collected feces were weighed then one gram of the faecal sample was suspended in distilled water and strained through a layer of gauze. After sedimentation for $1 \mathrm{~h}$ and subsequent centrifugation of the sediment at $1200 \mathrm{rpm}$ for 15 minutes, the obtained pellet was resuspended in distilled water up to a volume of $1 \mathrm{ml}$. The number of cysts per gram feces (CPG) was obtained (Xiao and Herd, 1993).

Histopathological examination of the small intestinal tissues: Paraffin sections of $5 \mu \mathrm{m}$ thickness were prepared, stained by haematoxylin and eosin (H\&E) for detection of the pathological changes and toluidine blue (TB) for counting of mast cells as TB can only stain the cytoplasmic granules of mast cells (Brandon and Evans, 1983). Five random sections / mouse were examined according to Scott et al. (2004). The mast cell numbers were counted at $400 \times$ magnification. The mast cell numbers in $1 \mathrm{~mm}^{2}$ area were calculated (Li et al, 2013). The intraepithelial lymphocytes (IELs) were counted along villus units. IELs were expressed as number per 100 epithelial cells (Scott et al, 2000).

Detection of interleukin-6 m RNA expression in small intestinal tissue: The intestinal samples were collected, grinded, exposed to liquid nitrogen, and then processed for total RNA extraction (MagNA pure compact nucleic acid isolation kit I, Roche Diagnostics, Germany) according to the manufacturer's recommendations. First strand cDNA was synthesized from total RNA using transcriptor first strand cDNA synthesis kit
(Roche, Germany). The mRNA level of IL6 was determined using competitive RTPCR technique according to Zhou et al. (2003) relative to the house-keeping gene, hypothanthine phosphoribosyl transferase (HPRT) using the Roche lightcycler ${ }^{\circledR}$ faststart DNA master plus Sybr green I kits (Roche Diagnostics, Germany). The primers used (Gulf Biotic, Saudi Arabia) generated bands of 201bp for IL-6 and $164 \mathrm{bp}$ for HPRT. IL-6 and HPRT were co-amplified for 45 cycles. Then, the PCR products were separated by electrophoresis in $20 \%$ agarose gel, stained with ethedium bromide, visualized by UV transilluminator and photography by Polaroid camera was done for permanent record. The intensity of bands was quantified by gel pro-analyzer version 3 and the results were analyzed by computer software (Biorad, UK).

Statistical analysis: Quantitative data were expressed as mean and standard deviation (mean \pm SD). Differences among groups were tested for significance by one-way analysis of variance (ANOVA) using Statistical Package for Social Sciences (SPSS) (SPSS Inc., Chicago, Illinois, USA), software for windows, version 14.0. Differences were considered insignificant at $P>0.05$, significant at $P<0.05$, highly significant at $P<0.01$ and extremely significant at $P<$ 0.001 .

\section{Results}

The number of $G$. lamblia cysts in the stool of IS mice was significantly higher than that from IC ones $(\mathrm{P}<0.001)$. Meanwhile there was a significant reduction in the cyst number four weeks PI as compared to two weeks PI in both IS and IC mice (Tab. 2).

There was shortening in villus height and increase in crypt depth in all infected groups. These changes were more pronounced in the IS infected group as compared to their respective group. Few numbers of goblet cells in intestinal villi are observed in IC and IS non-infected mice. Slight increase in the number of goblet 
cells is observed in the IS infected group while intestinal villi of IC infected mice showed marked increase in goblet cells. Moderate infiltration of the mucosa with lymphocytes was observed in the IC infected group while it is very mild in the IS infected group (Fig. $1 \& 2$ ). In the same context, the intraepithelial lymphocytic (IEL) count, there was also a significant increase in the number of IELs in IC and IS infected groups as compared to their respective controls at different time points. IEL numbers were significantly $(\mathrm{P}<0.001)$ lower in IS than in IC control groups. However, there was no significant difference in the number of IELs with time in the same group except in IC infected one (Tab. 3).
The small intestinal sections stained with TB showed that the number of mast cells increased in the mucosa after infection with G. lamblia in the IC mice as compared to the IC non-infected group. The mean number of mast cells per square millimeter achieved its highest values 2 weeks PI. However, mast cell count was significantly decreased in the IS infected group as compared to the IC infected group (Fig. 3 \&Tab. 4).

In IC mice, the infected group expressed high levels of IL-6 as compared to its control group that showed moderate expression. In IS mice, faint expression of IL-6 was detected in the infected group with absence of any expression of IL-6 in its respective control (Fig. 4).

Table 1: Primer sets for IL-6 and HPRT.

\begin{tabular}{|c|c|}
\hline Gene & Primers \\
\hline Il- 6 & $\begin{array}{c}\text { Forward: 5'-TCA ATG AGG AGA CTT GCC TGG-3` } \\
\text { Reverse: } 5 \text {-CAG CCA CTG GTT CTG TGC CT-3` }\end{array}$ \\
\hline HPRT & $\begin{array}{l}\text { Forward: } 5 \text {-GTT GGA TAC AGG CCA GAC TTT GTT G-3`} \\
\text { Reverse: } 5 \text {-GAT TCA ACT TGC GCT CAT CTT AGG C-3`}\end{array}$ \\
\hline
\end{tabular}

*Significant at $\mathrm{P}<0.05$, **Highly significant at $\mathrm{P}<0.01$

Table 2: Number of G. lamblia cysts/ gm stool of infected mice

\begin{tabular}{|c|c|c|c|}
\hline Experimental group & 2 weeks PI $($ mean \pm SD) & 4 weeks PI $($ mean \pm SD) & P \\
\hline$G p I($ IC, infected $)$ & $178 \pm 9.247$ & $66 \pm 7.583$ & $<0.01^{* *}$ \\
\hline$G p I I($ IS, infected $)$ & $198 \pm 11.389$ & $82.6 \pm 4.506$ & $<0.05^{*}$ \\
\hline \multicolumn{4}{|r|}{$\mathrm{P}<0.001$} \\
\hline
\end{tabular}

Table 3: Intraepithelial lymphocytes count/100 epithelial cells in small intestinal mucosa of mice of different groups.

\begin{tabular}{|c|c|c|c|}
\hline Experimental group & IELs 2 weeks PI (mean \pm SD) & IELs 4 weeks PI. (mean \pm SD) & P \\
\hline$G p I$ (IC, infected) & $7.37 \pm 0.393$ & $8.31 \pm 0.401$ & $<0.01^{* *}$ \\
\hline$G p$ II (IS, infected) & $4.81 \pm 0.271$ & $5.46 \pm 0.428$ & $>0.05^{\mathrm{ns}}$ \\
\hline$G P I I I$ (control IC group) & $6.63 \pm 0.285$ & $6.56 \pm 0.350$ & $>0.05^{\mathrm{ns}}$ \\
\hline$G P I V$ (control IS group) & $3.88 \pm 0.074$ & $3.56 \pm 0.356$ & $>0.05^{\mathrm{ns}}$ \\
\hline \multicolumn{2}{|c|}{$\mathrm{P}<0.001^{* * *}$} & & \\
\hline
\end{tabular}

Ns=insignificant at $P>0.05, * *$ Highly significant at $P<0.01, * * *$ Extremely significant at $P<0.001$ Table 4: Mast cell count (cell $/ \mathrm{mm}^{2}$ ) in small intestinal mucosa of mice of different groups.

\begin{tabular}{|c|c|c|c|}
\hline Experimental group & Mast cell 2 weeks PI (mean \pm SD) & Mast cell 4 weeks PI (mean \pm SD) & $\mathrm{P}$ \\
\hline$G p I(\mathrm{IC}$, infected $)$ & $107.8 \pm 9.418$ & $93.2 \pm 6.301$ & $<0.01 * *$ \\
\hline$G p I I($ IS, infected $)$ & $70.2 \pm 4.817$ & $65.6 \pm 4.827$ & $>0.05^{\mathrm{ns}}$ \\
\hline GP III (control IC group) & $84.2 \pm 3.194$ & $79.8 \pm 2.387$ & $>0.05^{\mathrm{ns}}$ \\
\hline$G P I V$ (control IS group) & $51 \pm 2.739$ & $50.8 \pm 3.271$ & $>0.05^{\mathrm{ns}}$ \\
\hline \multicolumn{3}{|c|}{$\mathrm{P}<0.001 * * *$} & \\
\hline
\end{tabular}

Ns=insignificant at $P>0.05, * *$ Highly significant at $P<0.01, * * *$ Extremely significant at $P<0.001$

\section{Discussion}

Giardiasis is a zoonosis which is considered an important public health problem in many countries worldwide. It infects about
200 million people in Asia, Africa, and Latin America (Yason and Rivera, 2007). G. lamblia is the most common causative agent of persistent diarrhea worldwide especially 
among children and travelers (Buret, 2008). Giardiasis becomes a self-limited illness in over $85 \%$ of affected individuals, indicating the existence of effective host defense mechanisms against the parasite (Grit et al, 2014). Ponce-Macotela et al. (2008) stated that the clinical manifestations of giardiasis represent the expression of host resistance and parasite virulence. Interestingly, cases of chronic giardiasis have been documented even in immunocompetent individuals and it is expected to worsen in immunosuppressed patients (Eckmann, 2003). It is usually presented by chronic diarrhea that could last for several months and may result in malabsorption and weight loss with increased mortality in malnourished or immune deficient individuals (Buret et al, 2002; Ankarklev et al, 2010; Cotton et al, 2011).

In the current study, the number of $G$. lamblia cysts in the stool of IS mice was significantly higher than that from IC ones with a peak at two weeks PI. Similar findings agreed with Jiménez et al. (2014). They found that the number of Giardia cysts in stool from infected mice was increased with a peak at 14 days PI. However, a reduction of the number of cysts was detected at 21 days PI and was low at 28 days PI. Several reports indicated that the clearance of Giardia in immunocompetent murine models occurs at approximately 3-5 weeks postinfection (Singer et al, 2000; Langford et al, 2002; Eckmann, 2003).

The clearance of Giardia from a host requires both innate and mucosal humoral and cellular immune responses. Innate immunity mechanisms are the first line of defense against colonization by pathogens (mucus, peristalsis, cytotoxic factors, NO, microbiota, mast cells and DC) (Lopez-romero et al, 2015). Also, there is adaptive immune response against Giardia that includes antigen-specific CD4+T cells, the release of cytokines, including IL-6, TNF- $\alpha$, IFN- $\gamma$ and $\mathrm{IL}-4$, and the production of specific IgA or IgG antibodies against parasite antigens (Roxtröm-Lind-quist et al, 2006; Zhou et al,
2007; Jimenez et al, 2014).Thus, immunosuppressed animals infected with $G$. lamblia had a high parasite load in the jejunum during all the phases of infection (Vinayak et al, 1989).

There was no significant histopathological changes in the small intestinal tissues in both IC and IS groups except some inflammatory cellular infiltration and increase in goblet cell number. These changes were more pronounced in the IS than in IC group. These results were in agreement with that of Wolfe (1992) who showed that patients with symptomatic giardiasis have a normal jejunal histological appearance with no inflammatory exudates. Little to no mucosal inflammation that was observed during giardiasis could be explained as G. lamblia does not invade the epithelial layer (Cotton et al, 2014).

The recruitment of DC and granulocytes and the activation of lymphocytes might even be diminished in response to the regulatory immune response in the intestine that is either induced by the host to reduce inflammation and immune-mediated pathology or induced by Giardia to promote its persistence in the intestine (Zhou et al, 2007; Dreesen et al, 2012). However, Yassien et al. (1996) reported severe atrophic changes in small intestinal villi of immunosuppressed mice which was explained by the high number of trophozoites which have direct injurious effect on the intestinal mucosa via their sucking discs. Moreover, Jiménez et al. (2004) described some histopathological changes in the small intestine after oral administration of Giardia E/S-Ags.

During the infectious process in the small intestine, goblet cells increase their production and release their secretions, as a protection mechanism from mucosal pathogens (Turner, 2009). The present study reported slight increase in the number of goblet cells that was observed in the IS infected group while marked increase in their numbers was observed in the intestinal villi of IC infected mice. The increase in the goblet cells repre- 
sents an initial step of the non-specific immune response. The mucus that is secreted by intestinal goblet cells impedes the pathogen access to the epithelia. Moreover, the trophozoites were adversely affected because mucin glycoproteins block the lectin receptors on the surface of the trophozoite, thus impairing the adherence of Giardia to epithelial cells (Roxtröm-Lindquist et al, 2006, Solaymani-Moha-mmadi and Singer, 2010). Therefore, in chronic giardiasis, patients lose intestinal barrier function resulting in reduced secretion of mucus and can contribute to the severe clinical manifestation of the infection (O'Hara and Buret, 2008; Halliez and Buret, 2013).

In the same manner, in the present study the observed shortening in the villus height in all infected groups that was more pronounced in the IS infected group. An increase in enterocyte apoptosis in giardiasis is reported to be correlated with reduction in villus height and an increase in intestinal barrier permeability, suggesting epithelial barrier dysfunction as a pathomechanism of diarrhea (Troeger et al, 2007; Cotton et al, 2011). The same findings regarding the villus height was observed in malnourished animals infected with Giardia, compared to control infected ones (Nichols et al, 2000; Ventura et al, 2013). This can be explained by decreased production of enterocytes in the villi, leading to decreases in both the number and the height of the villi (Pires et $a l, 2003)$. So, the results suggest that immunosuppression contributes to disease severity in giardiasis by decreasing the intestinal absorptive capacity via shortening of villi.

Regarding the IEL count, it was increased in both IC and IS infected groups as compared to their respective controls at different time points and their count was significantly lower in IS than in IC control groups. In the same context, increased numbers of IEL was observed in patients with chronic giardiasis. IEL are $\mathrm{T}$ cells that reside between intestinal epithelial cells, and they are comprised mainly of CD8+ T cells (Troeger et al, 2007).
In the present work, mast cell count was significantly increased in the IC infected group than in the IS infected group. Mast cells increase in the current study indicates that the $G$. lamblia infection induced the accumulation of mast cells in the mucosa of the small intestine of IC mice which is not the case in IS mice. Mast cells are recognized as effector cells of the immune response against Giardia. Interestingly, in tissues from the small intestine that have been infected with Giardia, the most strongly induced transcripts are mast cell proteases (Tako et al, 2013). Mast cells and NO may act together to induce peristalsis ( $\mathrm{Li}$ et al, 2006 ; Li et al, 2007). Mast cells can also contribute to B-cell activation and differentiation into plasma cells, driving the development of IgA (Merluzzi et al, 2010). Also, mast cells have a role in mediating smooth muscle contractions and contributing to changes in intestinal motility (SolaymaniMohammadi and Singer, 2010). Thus, IS mice showed delayed clearance of G. lamblia cysts. Similarly, it was reported that mast cell deficient mice that were infected with G. lamblia exhibit delayed parasite elimination as they fail to produce parasitespecific $\operatorname{Ig} \mathrm{A}$, indicating the important role for these cells in parasite immunity ( $\mathrm{Li}$ et al, 2004).

IL-6, a pro-inflammatory cytokine that is mainly elevated during giardiasis, induces innate cellular responses and also mediates B-cell switching to IgA and T-cell development into Th17 cells, which mediate early adaptive immune mechanisms (Kimura et al, 2007; Scheller et al, 2011). The results showed that IC infected mice expressed high levels of IL-6 while it was weak in IS mice. These results coincided with the finding reported by Bienz et al. (2003) that IL-6deficient mice fail to eliminate Giardia and also exhibit altered intestinal cytokine responses despite having normal levels of IgA. In addition to, Giardia lysates, excretorysecretory products and other specific proteins can activate the maturation of DC by 
increasing the expression of pro-inflammatory cytokines, such as IL-6 (Grit et al, 2014). Also, Zhou et al. (2003) showed that there was an increase in IL-6 expression in small intestine of mice that correlate with the control of Giardia infection at day 15 PI. The mechanism of IL- 6 production in small intestinal mucosa was explained by Singer and Nash (2000) who showed that $G$. lamblia infection stimulates the cellular immune response which in turn stimulates intra epithelial T-lymphocytes as well as lamina propria T-lymphocytes to secrete IL-6. Whereas, Li et al. (2004) showed that mast cells are a source of the IL-6 during $G$. lamblia infection and that IL-6 was required for efficient control of the infection. This finding correlated the decreased number of mast cells with decreased production of IL-6 in the IS mice which act together with decreased goblet cells and IELs resulting in decrease clearance of $G$. lamblia cysts as compare to the IC mice.

\section{Conclusion}

It was previously thought that IgA was the main mechanism that drove Giardia elimination from the intestine. However, in this work, we reports the importance of the innate immunity presented by goblet cells, mast cells and other adaptive immunity responses; IL-6 in the clearance of Giardia. The characterization of the protective responses associated with Giardia gives insights into host-parasite interactions and may help elimination and control of the parasite.

\section{References}

Ankarklev, J, Jerlström-Hultqvist, J, Ringqvist, E, Troell, K, Svärd, SG, 2010: Behind the smile: cell biology and disease mechanisms of Giardia species. Nat. Rev. Microbiol. 8:41322.

Anuar, TS, Moktar, N, Salleh, FM, Al-Mekhla-fi, HM, 2015: Human giardiasis in Malaysia: correlation between the presence of clinical manifestation and Giardia intestinalis assemblage. Southeast Asian J. Trop. Med. Pub. Hlth. 46, 5: 835-43.
Bienz, M, Dai, WJ, Welle, M, Gottstein, B, Muller, N, 2003: Interleukin-6-deficient mice are highly susceptible to Giardia lamblia infection but exhibit normal intestinal immunoglobulin A responses against the parasite. Infect. Immun. 71:1569-73.

Brandon, JM, Evans, JE, 1983: Changes in uterine mast cells during the estrous cycle in the Syrian hamster. Am. J. Anat.167:241-7.

Buret, AG, 2008: Pathophysiology of enteric infections with Giardia duodenalis. Parasite 15: 261-5.

Buret, AG, Mitchell, K, Muench, DG, Scott, KG, 2002: Giardia lamblia disrupts tight junctional ZO- 1 and increases permeability in nontransfor-med human small intestinal epithelial monolayers: effects of epidermal growth factor. Parasitol. 125, Pt 1:11-9.

Cheesbrough, M, 1987: Medical Laboratory Ma-nual for Tropical Countries, Tropical Health Technology, Butterworth, Heinmann.

Chin, AC, Teoh, DA, Scott, KG, Meddings, J B, Macnaughton, WK, et al, 2002: Strain-dependent induction of enterocyte apoptosis by $G i$ ardia lamblia disrupts epithelial barrier function in a caspase-3-dependent manner. Infect. Immun. 70, 7: 3673-80.

Cotton, JA, Amat, CB, Buret, AG, 2015: Disruptions of host immunity and inflammation by Giardia duodenalis: Potential consequences for co-infections in the gastro-intestinal tract. Pathogens 4, 4:764-92.

Cotton, JA, Beatty, JK, Buret, AG, 2011: Host parasite interactions and pathophysiology in $\mathrm{Gi}$ ardia infections. Int. J. Parasitol. 41:925-33.

Cotton, JA, Motta, JP, Schenck, LP, Hirota, S A, Beck, PL, et al, 2014: Giardia duodenalis infection reduces granulocyte infiltration in an in vivo model of bacterial toxin induced colitis and attenuates inflammation in human intestinal tissue. PLoS One, 9, e109087.

Dreesen, L, Rinaldi, M, Chiers, K, et al, 2012: Microarray analysis of the intestinal host response in Giardia duodenalis assemblage E infected calves. PLoS One 7, e40985.

Dyab, AK, Yones, DA, Ibraheim, ZZ, Hassan, T M, 2016: Anti-giardial therapeutic potential of di-chloromethane extracts of Zingiber officinale and Curcuma longa in vitro and in vivo. Parasitol. Res. DoI:10.1007/s00436-016-5010-9.

Eckmann, L, 2003: Mucosal defences against Giardia. Parasite. Immunol. 25:259-70. 
El-Kowrany, SE, Abd-El-Ghaffar, AE, Ghoraba, HM, 1996: Experimental heterophyiasis: The effect of immunosuppression on the course of the disease. Egypt. J. Med. Sci. 17, 2:481-97. Faubert, G, 2000: Immune response to Giardia duodenalis. Clin. Microbiol. Rev. 13, 1:35-54.

Gassama, A, Sow, PS, Fall, F, Camara, P, Guè-ye-N'diaye, A, et al, 2001: Ordinary and opportunistic enteropathogens associated with diarrhea in Senegalese adults in relation to human immunodeficiency virus serostatus. Int. J. Infect. Dis. 5, 4: 192-8.

Golami, S, Rahimi-Esboei, B, Mousavi, P, Marhaba, Z, Youssefi, MR, et al, 2016: Survey on efficacy of chloroformic extract of Artemisia annua against Giardia lamblia trophozoite and cyst in vitro. J. Parasit. Dis. 40, 1:88-92.

Grit, GH, Devriendt, B, Van Coppernolle, S, et al, 2014: Giardia duodenalis stimulates partial maturation of bovine dendritic cells associated with altered cytokine secretion and induction of T-cell proliferation. Parasit. Immunol. 36: 157-69.

Halliez, MC, Buret, AG, 2013: Extra-intestinal and long term consequences of Giardia duodenalis infections. World J. Gastroenterol. 19, 47: 8974-85.

Hill, DR, Nash, TE, 2015: Giardiais. In: Bennet's Principles and Practice of Infectious Disease. (Eds. JE, Bennett, R, Dolin, MJ,. Blaser) Mandell, Douglas, Vol. 281; Saunders, Elsevier. Jiménez, JC, Fontaine, J, Creusy, C, Fleurisse, L, Grzych, JM, et al, 2014: Antibody and cytokine responses to Giardia excretory/ secretory proteins in Giardia intestinalis-infected BALB/c mice. Parasitol. Res. 113, 7:2709-18.

Jiménez, JC, Fontaine, J, Grzych, JM, DeiCas, E, Capron, M, 2004: Systemic and mucosal responses to oral administration of excretory/ secretory (E/S) antigens from Giardia intestinalis. Clin. Diagn. Lab. Immunol. 11, 1:152-60.

Kamda, JD, Nash, TE, Singer, SM, 2012: $G i-$ ardia duodenalis: dendritic cell defects in IL-6 deficient mice contribute to susceptibility to intestinal infection. Exp. Parasitol.130:288-91.

Kimura, A, Naka, T, Kishimoto, T, 2007: IL6-dependent and -independent pathways in the development of interleukin 17-producing $\mathrm{T}$ helper cells. Proc. Natl. Acad. Sci. U.S.A. 104: 12099-104.

Lane, S, Lloyd, D, 2002: Current trends in research into the waterborne parasite Giardia. Crit. Rev. Microbiol. 28:123-47.
Langford, TD, Housley, MP, Boes, M, Chen, J, Kagnoff, MF, et al, 2002: Central importance of immunoglobulin $\mathrm{A}$ in host defense against Giardia spp. Infect. Immun.70, 1:11-8.

Li, E, Zhao, A, Shea-Donohue, T, Singer, SM, 2007: Mast cell-mediated changes in smooth muscle contractility during mouse giardiasis. Infect. Immun.75:4514-8.

Li, E, Zhou, P, Petrin, Z, Singer, SM, 2004: Mast cell-dependent control of Giardia lamblia infections in mice. Infect. Immun. 72:6642-9.

Li, E, Zhou, P, Singer, SM, 2006: Neuronal nitric oxide synthase is necessary for elimination of Giardia lamblia infections in mice. J. Immunol. 176: 516-21.

Li, S, Li, W, Yang, Z, Song, S, Yang, J, et al, 2013:Infection of cattle with Cryptosporidium par-vum: Mast cell accumulation in small intestine mucosa. Vet. 50, 5:842-8.

Lopez-Romero, G, Quintero, J, AstiazaránGa-rcía, H, Velazquez, C, 2015: Host defences again-st Giardia lamblia. Parasit. Immunol. 37, 8:394-406.

Merluzzi, S, Frossi, B, Gri, G, Parusso, S, Tripodo, C, Pucillo, C, 2010: Mast cells enhance proliferation of B lymphocytes and drive their differentiation toward IgA-secreting plasma cells. Blood 115, 14:2810-7.

Nichols, BL, Nichols, VN, Putman, M, Avery, SE, Fraley, JK, et al, 2000: Contribution of villous atrophy to reduced intestinal maltase in infants with malnutrition. J. Pediatr. Gastroenterol. Nutr. 30, 5:494-502.

O'Hara, JR, Buret, AG, 2008: Mechanisms of in-testinal tight junctional disruption during infection. Front. Biosci. 13:7008-21.

Panaro, MA, Cianciulli, A, Mitolo, V, Mitolo, C I, Acquafredda, A, et al, 2007: Caspasedependent apoptosis of the HCT-8 epithelial cell line induced by the parasite Giardia intestinalis. FEMS Immunol. Med. Microbiol. 51, 2:302-9.

Pires, AL, da Silveira, TR, da Silva, VD, 2003: Digital morphometric and stereologic analysis of small intestinal mucosa in wellnourished and malnourished children with persistent diarrhea. J. Pediatr. Rio J., 79, 4:329-36.

Ponce-Macotela, M, González-Maciel, A, Reynoso-Robles, R, Martínez-Gordillo, MN, 2008: Goblet cells: are they an unspecific barrier against Giardia intestinalis or a gate? Parasitol. Res.102, 3:509-13.

Roxtröm-Lindquist, K, Palm, D, Reiner, D, 
Rin-gqvist, E, Svärd, G, 2006: Giardia immunity: An update. Trends Parasitol. 22:26-31.

Saghaug, CS, Sørnes, S, Peirasmaki, D, Svärd, S, Langeland, N, Hanevik, K, 2015: Human me-mory CD4+ T cell immune responses against Gia-rdia lamblia. Clin. Vaccine Immunol. 23, 1:11-8.

Scheller, J, Chalaris, A, Schmidt-Arras, D, Ro-se-John, S, 2011: The pro- and antiinflammatory properties of the cytokine interleukin- 6. Biophys. Acta. 1813:878-88.

Scott, KGE, Logan, MR, Klammer, GM, Theoh, DA, Buert, AG, 2000: Jejunal brush border microvillous altrations in Giardia muris-infected mice: Role of T lymphocytes and interleukin-6. Infect. Immun. 68, 6:3412-8.

Scott, KGE, Yu, LCH, Buert, AG, 2004: Role of CD8+ and CD4+T lymphocytes in jejunal mucosal injury during murine giardiasis. Infect. Immun. 72, 6:3536-42.

Singer, SM, Nash, TE, 2000: T-cell-dependent control of acute Giardia lamblia infections in mice. Infect. Immun. 68:170-5.

Solaymani-Mohammadi, S, Singer, SM, 2010: Giardia duodenalis: The double-edged sword of immune responses in giardiasis. Exp. Parasitol. 126, 3:292-7.

Stark, D, Barratt, JL, van Hal, S, Marriott, D, Harkness, J, et al, 2009: Clinical significance of enteric protozoa in the immunosuppressed human population. Clin. Microbiol. Rev. 22, 4:634-50.

Tako, EA, Hassimi, MF, Li, E, Singer, SM, 2013: Transcriptomic analysis of host response to Giardia duodenalis infection reveals redundant mechanisms for parasite control. M. Bio.4, e00660-13.

Troeger, H, Epple, HJ, Schneider, T, et al, 2007: Effect of chronic Giardia lamblia infec- tion on epithelial transport and barrier function in human duodenum. Gut 56:328-35.

Turner, JR, 2009: Intestinal mucosal barrier function in health and disease. Nat. Rev. Immunol. 9:799-809.

Ventura, LL, Oliveira, DR, Viana, JC, Santos, J F, Caliari, MV, Gomes, MA, 2013: Impact of protein malnutrition on histological parameters of experimentally infected animals with Giardia lam-blia. Exp. Parasitol.133, 4:391-5.

Vinayak, VK, Khanna, R, Kum, K, 1989: Sequential changes of lamina propria immunoglobulin-containing cells in immune intact and immunosuppressed mice infected with Giardia lamblia. Cell Biol. 67, Pt 3:177-82.

Wolfe, MS, 1992: Giardiasis. Clin. Microbiol. Rev. 5, 1:93-100.

Xiao, L, Herd, RP, 1993: Quantitation of $\mathrm{Gi}^{-}$ ard- ia cysts and Cryptosporidium oocysts in fecal sam-ples by direct immunofluorescence assay. J. Clin. Microbiol. 31:2944-6

Yason, JA, Rivera, WL, 2007: Genotyping of Gi-ardia duodenalis isolates among residents of slum area in Manila, Philippines. Parasitol. Res. 101: 681-7.

Yassien, NA, el-Kowrany, SE, Atta, FA, Ghora-ba, H, 1996: Immunological and histopathological study on splenectomized mice infected with Giardia lamblia. J. Egypt. Soc. Parasitol. 26, 3: 661-9.

Zhou, P, Li, E, Shea-Donohue, T, Singer, SM, 2007: Tumour necrosis factor alpha contributes to protection against Giardia lamblia infection in mice. Parasit. Immunol. 29:367-74.

Zhou, P, Li, E, Zhu, N, Robertson, J, Nash, T, Singer, SM, 2003: Role of interleukin-6 in the control of acute and chronic Giardia lamblia infections in mice. Infect. Immun.71:1566-8.

\section{Legends of figures}

Fig. 1: Histopathological changes of small intestine of mice infected with G. lamblia (H\&E, $\times 400)$ : (A\&B) IC mice showing intact mucosa with moderate inflammatory infiltrates mainly of lymphocytes in mucosa and submucosa, (C) IS mice showing many tro-phozoites adherent to mucosal cells and (D) IS mice showing mild inflammatory infiltrates in mucosa and submucosa.

Fig. 2: Histopathological changes of small intestine of IS mice infected with G. lamblia (H\&E, $\times 200)$ : (A\&B) showing pronounced shortening in villus height and increase in crypt depth.

Fig. 3: Intestinal mucosa of mice infected with G. lamblia (TB, $\times 400)$ : (A \&B) IC mice showing accumulation mast cells and (C\&D) IS mice showing lower numbers of mast cells.

Fig. 4: Gel electrophoresis of RT-PCR product of IL-6 in small intestinal tissue of G. lamblia infected mice 2 weeks PI (stained by ethium bromide); lane 1: molecular size marker, lane 2: external standard, lane 3, 4: marked expression in IC infected group, lane 5, 6: moderate expression in control IC group, lane 7: faint expression in IS infected group $\&$ lane 8: no expression in control IS group 


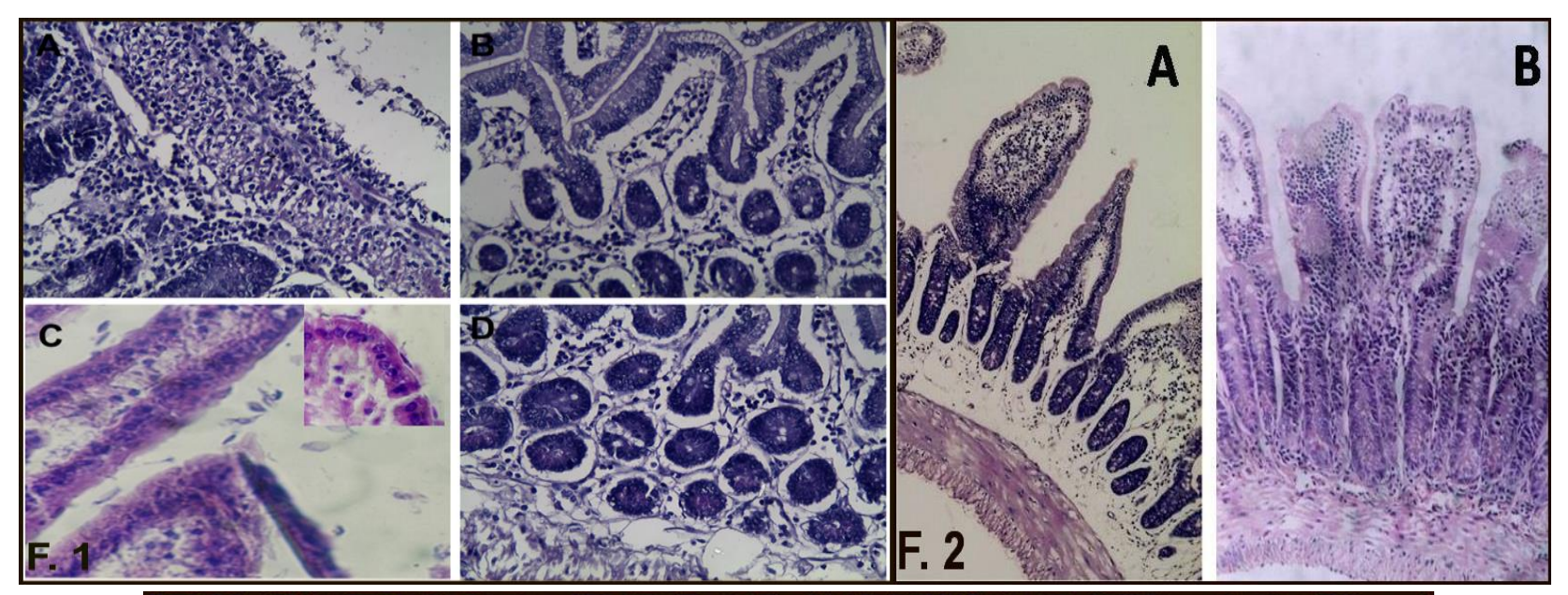
A.5 0 . 6 -

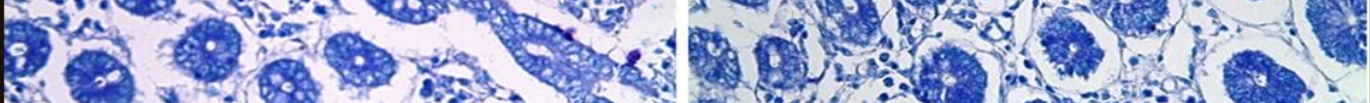

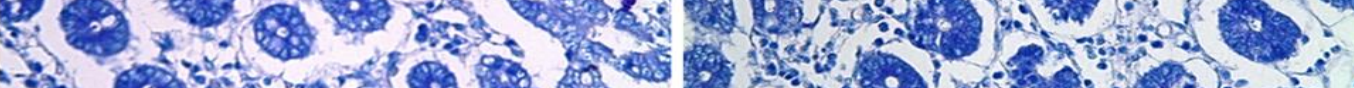

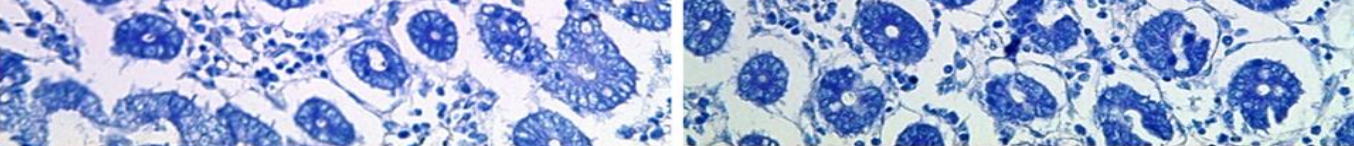

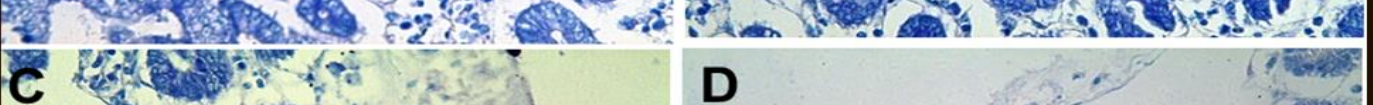
C. $\ldots$ D. D

Mon

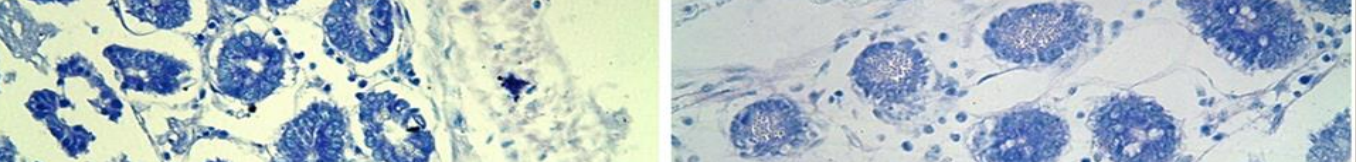

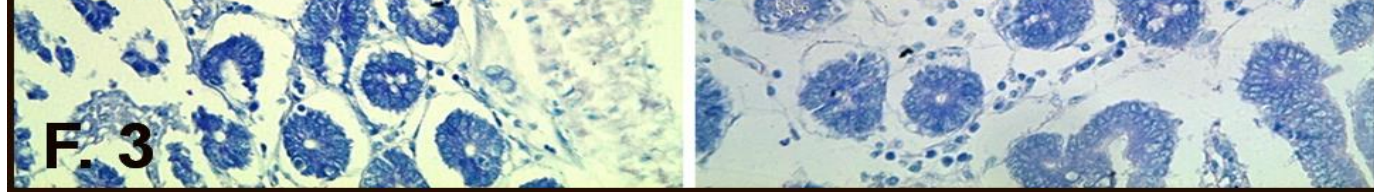

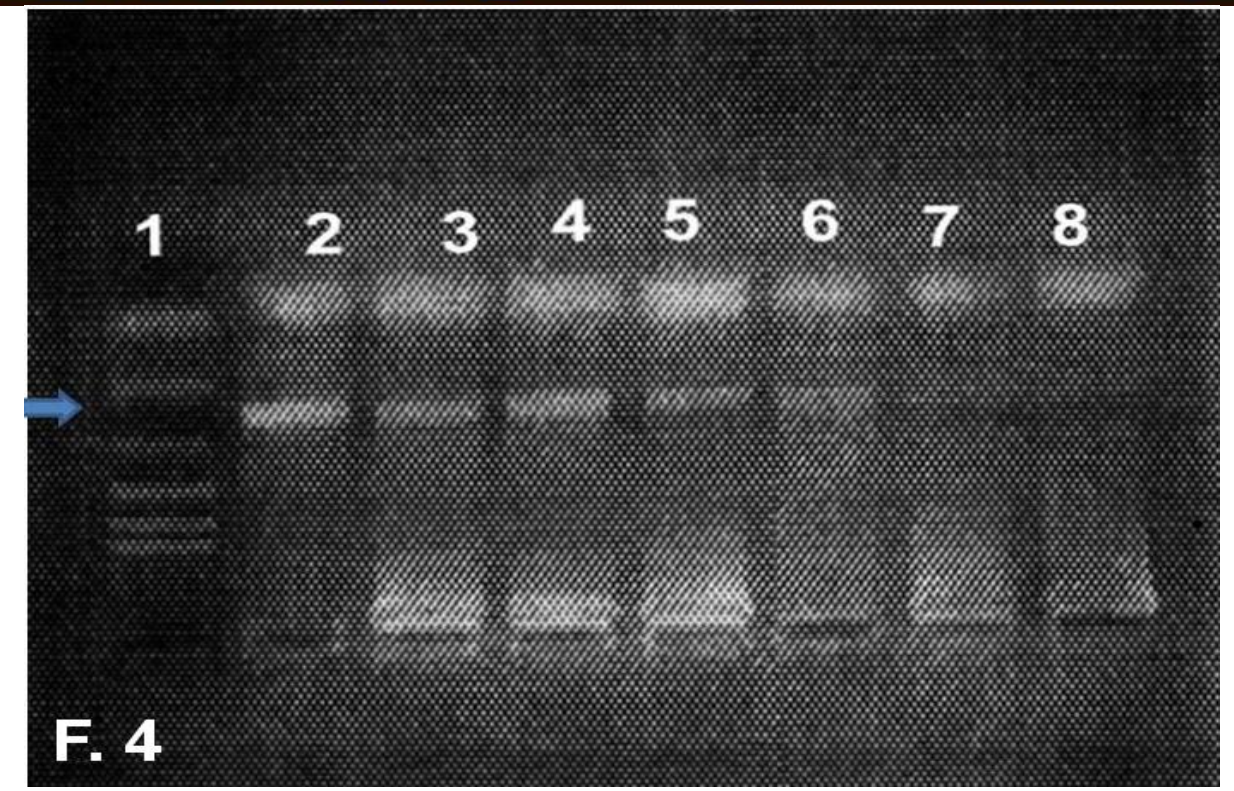

